\title{
Thermal degradation of poly(alkyl methacrylates) and polyurethane pressure-sensitive adhesives
}

\author{
Krzysztof Zych*, Robert Pełech, Zbigniew Czech \\ West Pomeranian University of Technology, Szczecin, Institute of Organic Chemical Technology, ul. Pulaskiego 10, \\ 70-322 Szczecin, Poland, \\ "Corresponding author: e-mail: zyniek@o2.pl
}

\begin{abstract}
Gas chromatography, coupled with the temperature controlled pyrolysis technique, can be used as a quick method of identification of polymers such as acrylates, methacrylates and polyurethanes. Polymers based on alkyl methacrylates are widely used as construction materials and coatings. Polyurethanes are widely used as self-adhesives, sealants and electrical products (due to polyurethane's low glass transition temperature $\mathrm{T}_{\mathrm{g}}$ ). The aim of this work is to investigate which products can be obtained from polymethacrylates and polyurethanes.
\end{abstract}

Keywords: chromatography, poly(alkyl acrylates), polyurethanes, solvent polymerization, thermal degradation, pyrolysis.

\section{INTRODUCTION}

Polymer organic materials are widely used as protective coatings to match with the appearance and properties of the covered surface. During and after application some amount of waste is produced. This can arise in the form of cuttings after mechanical working or as a residue from the spreading process. A part of the waste results from failures and unpredictable accidents.

Methacrylate copolymers with excellent physical, chemical and mechanical properties are widely used in many applications such as raw materials for adhesives, paints, varnishes and sealants in technical and medical areas. Plastics based on alkyl methacrylates are widely used as construction materials and coatings. Their properties depend particularly on the type of alkyl group in the side chain. Chain branching enhances hardness while elongation increases plasticization ${ }^{\mathbf{1}}$.

One of the methods for disposing of polymeric wastes could be pyrolysis. Pyrolysis gas chromatography (Py-GC) is a method, which may be easily, rapidly and inexpensively used to characterize a polymer formulation: polymer or a compounded polymeric material ${ }^{2-3}$. Pyrolysis, using the properly chosen conditions, may be used to transform waste into useful products. Especially for polyacrylates and polymethacrylates, the polymer is degradable to regenerate monomer ${ }^{4-6}$. When using pyrolysis coupled with gas chromatography a pattern of degradation products characteristic of a particular polymer may be observed. This serves to identify the material undergoing pyrolysis ${ }^{7}$.

In this study the use of pyrolysis as a method of identification of thermal degradation of polymethacrylates and polyurethanes is presented.

\section{EXPERIMENTAL}

\section{Materials}

The investigated polymers were synthesized from the following methacrylates: methyl, ethyl, butyl and 2-ethylhexyl. The polymerizations were performed in ethyl acetate at $77^{\circ} \mathrm{C}$ in a nitrogen atmosphere in the presence of 2,2'-azo-bis-diisobutyronitryle (AIBN) as an initiator.

The polyurethane PSA's were synthesized in the absence of the solvent at $85^{\circ} \mathrm{C}(2 \mathrm{~h}$ in a nitrogen atmosphere) from isophorone diisocyanate (IPDI), polypropylene glycol (PPG), hydroxytelechelic polybutadiene (HTPB), dimethylolpropionic acid (DMPA) catalyzed by dibutyltin dilaurate (DBTL). After $2 \mathrm{~h}$, the temperature was reduced to $85^{\circ} \mathrm{C}$, and aliquots were removed for the NCO content determination. The mixture was neutralized by heating with triethylamine (TEA) at $50^{\circ} \mathrm{C}$ for $1 \mathrm{~h}$. The temperature was subsequently reduced to $25^{\circ} \mathrm{C}$, and the polyurethane was dispersed in water with high-speed stirring. Ethylenediamine (EDA) was added to the dispersion, and the reaction was maintained at $35^{\circ} \mathrm{C}$ for $1 \mathrm{~h}$ to complete the chain-extension reaction between the amino groups of the chain extender and the NCO end groups of the polyurethane polymer. The synthesized polyurethane PSA dispersion was dried for $10 \mathrm{~min}$ at $110^{\circ} \mathrm{C}$ in a drying oven.

\section{Pyrolysis}

The pyrolysis of polmethacrylates was conducted in a quartz flask containing a $5 \mathrm{~g}$ sample which were heated to the desired temperature in an electric furnace. The flask was connected to a condenser, where the liquid products of pyrolysis were condensed. These products were collected in a flask under the condenser. The flask was equipped with a bottom outlet valve, which enabled the ready sampling of the condensate. The outlet of the condenser was closed with a hydraulic valve, which enabled the collection of gas samples. The top of the column was closed with a membrane which facilitated the sampling of the gaseous products of the pyrolysis.

Polyurethane PSA (in theform of the dried film) was pyrolyzed in a microreactor connected to the gas chromatograph. Pyrolysis was conducted in a stream of carrier gas at $600^{\circ} \mathrm{C}$ with a heating time of 5 seconds.

\section{Identification of products}

The products of the pyrolysis of polymethacrylates were analyzed by gas chromatography. The quantity of the liq- 
uid products from the pyrolysis was determined using an internal standard. As an internal standard, 1-bromonaphatalene was used. Determination of the products was conducted using a ThermoScientific GC8000 Top gas chromatograph and the following conditions: capillary column - RESTEK RTX-5 $30 \mathrm{~m}, 0.53 \mathrm{~mm}, 1,5 \mu \mathrm{m}$ film, carrier gas - helium $(50 \mathrm{kPa})$, detector - FID, oven - temperature programme: $45^{\circ} \mathrm{C}(4 \mathrm{~min})$ increment $10^{\circ} \mathrm{C} /$ $\min$ to $320^{\circ} \mathrm{C}$.

Gaseous products from the pyrolysis of polymethacrylates were analyzed using gas chromatography and an external standard method. The determination of these products was conducted using a ThermoScientific TraceUltra gas chromatograph and the following conditions: capillary column - RESTEK RT-Q-BOND $30 \mathrm{~m}$, $0.53 \mathrm{~mm}$, carrier gas - helium $(5 \mathrm{~cm} 3 / \mathrm{min})$, detector $\mathrm{TCD}$, oven - temperature programme: $50^{\circ} \mathrm{C}(5 \mathrm{~min})$ increment $10^{\circ} \mathrm{C} / \mathrm{min}$ to $280^{\circ} \mathrm{C}$.

The breakdown products of the investigated polyurethane PSA's were separated using

a glass chromatographic column packed with poly(ethylene glycol) 1000 (15\%) on Chromosorb P 60/ 80 mesh.: column length $-3 \mathrm{~m}$; temperature $-100^{\circ} \mathrm{C}$; carrier gas - helium; flow rate $-30 \mathrm{ml} / \mathrm{min}$. Under these conditions the components with high boiling points irreversibly adsorbed to the column in the first section of the chromatographic column. Mass spectra of the main components were obtained at the top of the maximum elution volume (corresponding to the top of the chromatographic peak) using an ionization energy of $70 \mathrm{eV}$ and an ion source temperature at $200^{\circ} \mathrm{C}$.

\section{RESULTS AND DISCUSSION}

At temperatures below $400^{\circ} \mathrm{C}$ the main decomposition products of poly(alkyl methacrylates) are monomers from which the polymer was formed. Above $500^{\circ} \mathrm{C}$ the amount of monomer in pyrolysis mixture decreases dramatically. The liquid products from pyrolysis contain alcohols from methacrylate ester. This is particularly the case for the esters derived from larger alcohols, 2-ethylhexyl methacrylate and 2-ethylhexen-1. For polymers derived from methacrylate esters of smaller (ethyl, butyl) alcohols, the corresponding olefins (ethane, butene) were found. For the samples pyrolyzed above $700^{\circ} \mathrm{C}$, about $75 \%$ mass of the products are gaseous products. These are mainly carbon dioxide, carbon oxide and methane. These are formed in roughly equal amounts

The products of pyrolysis of poly(ethyl methacrylate) at different temperatures are presented in Table 1.

The results from the pyrolysis of polyurethane PSA's indicate that the major products of thermal degradation are predominantly the raw materials used for the synthesis of the polyurethane PSA dispersions: IPDI, PPG, HTPB, TEA, and EDA. Thermal degradation of polymers containing carboxylic groups produced water as a by-product of anhydride formation along the polymer backbone ${ }^{8}$. The

Table 1. Products of pyrolysis of poly(ethyl methacrylate)

\begin{tabular}{|c|c|c|c|c|c|c|}
\hline \multirow[t]{2}{*}{ Products of pyrolysis } & \multicolumn{6}{|c|}{ Temperature of pyrolysis $\left[{ }^{\circ} \mathrm{C}\right]$} \\
\hline & 300 & 400 & 500 & 600 & 700 & 800 \\
\hline & \multicolumn{6}{|c|}{ mass $\%$ related to batch } \\
\hline $\mathrm{CO}_{2}$ & 0.4 & 0.8 & 1.4 & 6.0 & 22.6 & 23.1 \\
\hline $\mathrm{CO}$ & 0.6 & 1.2 & 1.6 & 5.4 & 22.2 & 22.0 \\
\hline $\mathrm{CH}_{4}$ & - & 0.7 & 2.2 & 4.0 & 16.2 & 17.2 \\
\hline Ethane & - & - & 0.3 & 0.6 & 0.8 & 1.6 \\
\hline Methanol & - & - & 0.3 & 0.8 & 2.6 & 3.3 \\
\hline Ethanol & 0.3 & 1.5 & 2.2 & 4.0 & 6.0 & 6.0 \\
\hline Propanol & - & 1.3 & 2.0 & 4.0 & 5.8 & 6.0 \\
\hline
\end{tabular}

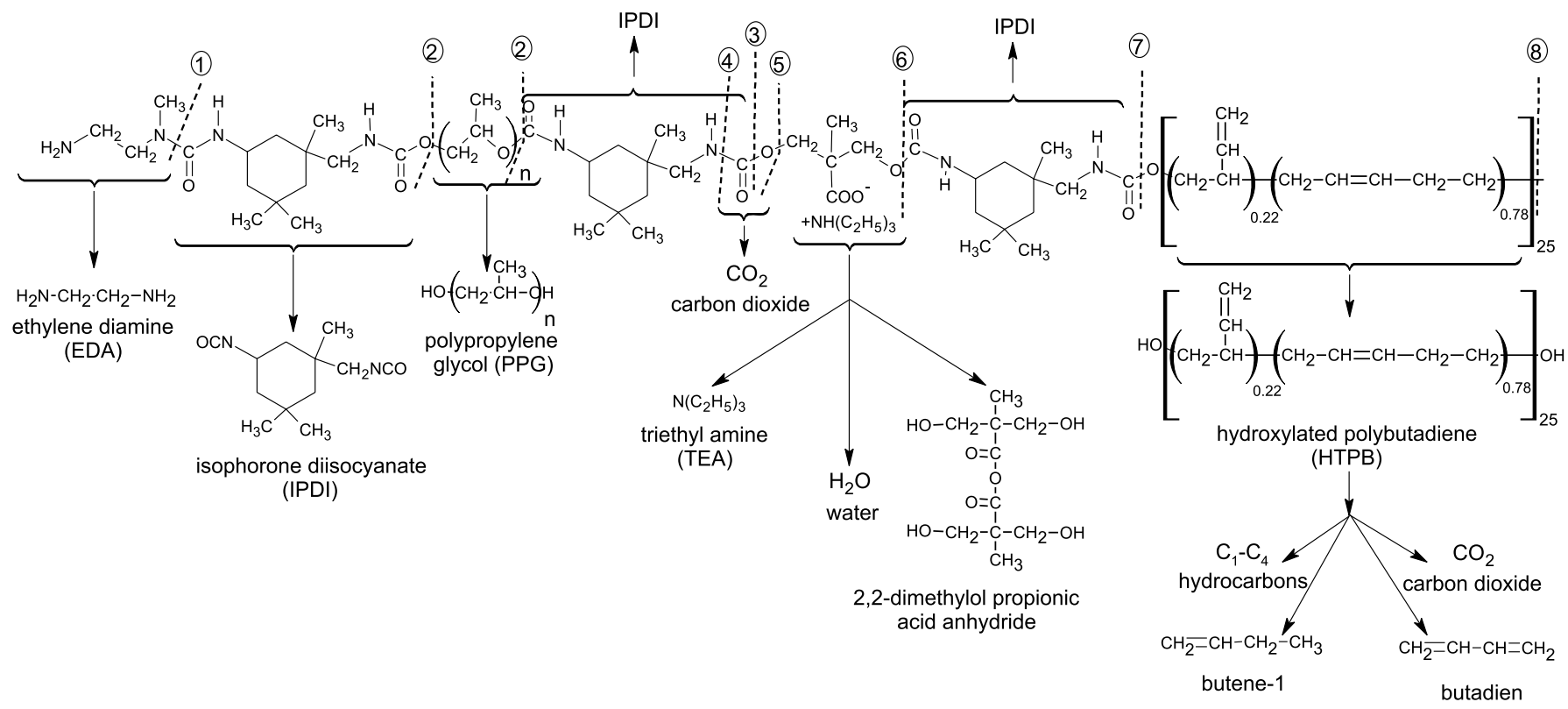

Figure 1. Thermal degradation of synthesized polyurethane PSA 
quantity of water (formed during the pyrolysis of carboxylated polyurethane polymers containing carboxylic groups) was directly proportional to the number of carboxylic groups incorporated into the polymer backbone. Dimethylolpropionic acid was not observed among the products during thermal degradation. The pyrolysis products of polyurethane PSAs obtained from cycloaliphatic diisocyanate IPDI were similar, except that the breakdown products corresponding to $\mathrm{C}_{1}-\mathrm{C}_{4}$ hydrocarbons (methane, ethane, propane, and butane) were observed (Table 2). The unsaturated components in the pyrolyzate were butane- 1 and butadiene. Both products were derived from hydroxytelechelic polybutadiene segments.

The results showed that IPDI and PPG were the main pyrolysis products of typical cycloaliphatic polyurethane PSAs. Decarboxylation of the polymer at higher temperatures was evidenced by the presence of carbon dioxide in the pyrolysis product mixture. A scheme to amount for the decomposition of typical polyurethane polymers to form diisocyanates, poly(alkyl glycols), and carbon dioxide is shown in Figure 1.

The thermal destruction of the polyurethane PSA chain is also illustrated in Figure 1. The scission (1) typically formed an EDA fragment. The main chain scissions (1)/(2), (2)/3), and (6/7) produced IPDI, and scission (2) resulted in PPG. The fragment produced by the decarboxylation process, (4) and (5), was carbon dioxide, and the chain fragment produced by scissions (5) and (6) was dimethylolpropionic acid, detected as dimethylolpropionic anhydride. Thermal fragmentation via scissions (7) and (8) yielded HTPB and the breakdown products of HTPB, such as butene-1 and butadiene.

The identities and concentrations of the major breakdown products from the thermal degradation of polyurethane PSA at $600^{\circ} \mathrm{C}$ are shown in Table 2.

Table 2. Breakdown products from the pyrolysis of polyurethane PSA

\begin{tabular}{|c|c|c|}
\hline Product No. & Chemical name and structure & Concentration (wt.\%) \\
\hline 1 & $\begin{array}{c}\mathrm{NH}_{2}-\mathrm{CH}_{2}-\mathrm{CH}_{2}-\mathrm{NH}_{2} \\
\text { ethylenediamine (EDA) }\end{array}$ & 3.2 \\
\hline 2 & $\mathrm{O}=\mathrm{C}=\mathrm{N}$ & 40.4 \\
\hline 3 & $\begin{array}{c}\stackrel{\mathrm{CH}_{3}}{\mathrm{l}} \\
\mathrm{HO}\left(\mathrm{CH}_{2}-\stackrel{\mathrm{CH}}{\mathrm{O}}-\right)_{\mathrm{n}} \mathrm{H} \\
\text { polypropylene glycol (PPG) } \\
\overline{\mathrm{M}}_{\mathrm{w}}=1010 \text { or } \overline{\mathrm{M}}_{\mathrm{w}}=2000\end{array}$ & 20.8 \\
\hline 4 & $\begin{array}{c}\mathrm{CO}_{2} \\
\text { carbon dioxide }\end{array}$ & 10.7 \\
\hline 5 & $\begin{array}{c}\qquad\left(\mathrm{C}_{2} \mathrm{H}_{5}\right)_{3} \mathrm{~N} \\
\text { triethylamine (TEA) }\end{array}$ & 2.1 \\
\hline 6 & $\begin{array}{c}\mathrm{H}_{2} \mathrm{O} \\
\text { water }\end{array}$ & 1.5 \\
\hline 7 & 2,2-dimethylolpropionic acid anhydride & 2.3 \\
\hline 8 & 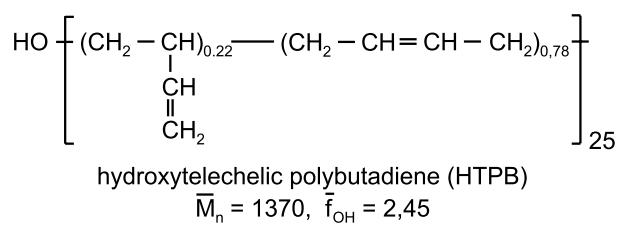 & 10.4 \\
\hline 9 & $\begin{array}{c}\mathrm{C}_{1}-\mathrm{C}_{4} \text { hydrocarbons } \\
\text { (methane, ethane, propane, butane) }\end{array}$ & 1.2 \\
\hline 10 & $\begin{array}{c}\mathrm{CH}_{2}=\mathrm{CH}-\mathrm{CH}-\mathrm{CH}_{2} \\
\text { butene-1 }\end{array}$ & 4.1 \\
\hline 11 & $\begin{array}{c}\mathrm{CH}_{2}=\mathrm{CH}-\mathrm{CH}=\mathrm{CH}_{2} \\
\text { butadiene }\end{array}$ & 1.6 \\
\hline 12 & other & 4.9 \\
\hline
\end{tabular}




\section{CONCLUSIONS}

It has been found that pyrolysis of polymethacrylates: methyl, ethyl, butyl and 2-ethylhexyl at temperatures below $400^{\circ} \mathrm{C}$ gives mainly monomers as a result of the mainchain decomposition. At higher temperatures gaseous products, which contain $\mathrm{CO}_{2}, \mathrm{CO}$ and methane, are formed. For polymers derived from methacrylate esters of larger alcohols, the pyrolysate contained the corresponding aliphatic alcohols. The results indicate that pyrolysis may be used to recover monomers from waste polymethacrylates.

This study of the thermal degradation of polyurethane pressure-sensitive adhesive dispersions, utilizing pyrolysis gas chromatography permits a detailed analysis of the product mixture from degradation, especially the detection of raw materials used for the synthesis of the polyurethane PSA dispersions. This technique may prove useful to solve the problems related to the production of polyurethane polymeric materials in the form of adhesives, sealants, foams, and pressure-sensitive adhesives, and for monitoring the production and properties of the decomposition products of polyurethanes.

\section{LITERATURE CITED}

1. Czech, Z., (1999) Crosslinking of Pressure-Sensitive Adhesives Based on Acrylics. Szczecin University of Technology, Szczecin.

2. Wang, F. \& Burleson, A., (1999) The development of pyrolysis-fast gas chromatography for analysis of synthetic polymers, J. Chromatogr A., 833, 111 - 119.

3. Howell, B.A., Spears, D.A. \& Smith, P.B., (2006) Thermal degradation of vinylidene chloride/[4-(tbutoxycarbonyloxy)phenyl]methyl acrylate copolymers, J. Ther. Anal. Cal., 85, 115 - 117, DOI: 10.1007/s10973-005-7481-2.

4. Czech, Z. \& Pełech, R., (2009) The thermal degradation of acrylic pressure-sensitive adhesives based on butyl acrylate and acrylic acid, Prog. Org. Coat. 65, 84 - 87, DOI:10.1016/ j.porgcoat.2008.09.017.

5. Czech, Z. \& Pełech, R., (2009) Thermal degradation of butyl acrylate-methyl acrylate-acrylic acid-copolymers, J. Therm. Anal. Cal. 96, 583 - 586, DOI: 10.1007/s10973-008-9226-5.

6. Czech, Z. \& Pełech, R., (2009) Thermal degradation of solvent-borne water-soluble acrylic acid-butyl acrylate-copolymers, Mater. Sci. Poland. 2, 851 - 856.

7. Czech, Z. \& Pełech, R., (2008) Use of pyrolysis and gas chromatography for the determination of acrylic acid concentration in acrylic copolymers containing carboxylic groups. Polym. Test. 27, 870 - 872, doi:10.1016/ j.polymertesting.2008.06.009.

8. Czech, Z., Cieślik, M., Wesołowska, M. \& Łagiewczyk, M., (2008) Solvent - Free Acrylic and Polyurethane Pressure Sensitive Adhesives, Pol. J. Chem. 82, 2331 - 2340. 